\title{
The selective cytotoxicity elicited by phytochemical extract from Senecio graveolens (Asteraceae) on breast cancer cells is enhanced by hypoxia
}

\author{
CARLOS ECHIBURÚ-CHAU ${ }^{1,2}$, SUSANA ALFARO-LIRA ${ }^{2}$, NELSON BROWN ${ }^{3}$, CRISTIAN O. SALAS ${ }^{4}$, \\ MAURICIO CUELLAR ${ }^{5}$, JAVIER SANTANDER ${ }^{6}$, JUAN PABLO OGALDE ${ }^{7}$ and FRANCISCO ROTHHAMMER ${ }^{8}$ \\ ${ }^{1}$ Centro de Investigaciones del Hombre en el Desierto (CODECITE-CIHDE), Arica; ${ }^{2}$ Departamento de Biología, \\ Facultad de Ciencias, Universidad de Tarapacá, Arica; ${ }^{3}$ Escuela de Medicina, Universidad de Talca, Talca; \\ ${ }^{4}$ Departamento de Química Orgánica, Facultad de Química, Pontificia Universidad Católica de Chile, Santiago; \\ ${ }^{5}$ Facultad de Farmacia, Universidad de Valparaíso, Valparaíso; ${ }^{6}$ Nucleus for Microbiology and Immunity, \\ Center for Genomics and Bioinformatics, Faculty of Sciences, University Mayor, Santiago; ${ }^{7}$ Departamento de Química, \\ Universidad de Tarapacá, Arica; ${ }^{8}$ Instituto de Alta Investigación, Universidad de Tarapacá, Arica, Chile
}

Received November 24, 2013; Accepted January 23, 2014

DOI: $10.3892 /$ ijo.2014.2302

\begin{abstract}
Breast cancer is the second cause of cancer-related deaths in woman and the incidence of the disease has increased worldwide, in part due to improvements in early detection. Several drugs with anticancer effects have been extracted from plants in the last 20 years, many of which are particularly effective against breast cancer cells. In particular, we have become interested in the ethanolic extract from Senecio graveolens (synonym of $S$. nutans), a plant commonly called Chachacoma, in an effort to isolate compounds that could demonstrate cytotoxic effects on breast cancer cells. Senecio (Asteraceae) is the largest gender in Chile comprising approximatly 200 species. These herbs inhabit areas over 3,500 meters above the sea level in the Andes Mountains. S. graveolens is commonly used by local communities for its medicinal properties, particularly its capacity to ameliorate high-altitude-associated sickness. The cytotoxic effect of the alcoholic extract from $S$. graveolens, as well as its most abundant compound 4-hydroxy-3-(3-methyl2-butenyl)acetophenone, were tested in the breast cancer cell lines ZR-75-1, MCF-7 and MDA-MB-231, and non-tumorigenic MCF-10F cells. We show that the phytochemical extract was able to induce cytotoxicity in cancer cells but not in MCF-10F. Importantly, this effect was enhanced under hypoxic conditions. However, 4-hydroxy-3-(3-methyl-2-butenyl)acetophenone, the main compound, did not by itself show an effective anticarcinogenic activity in comparison to the whole extract. Interestingly,
\end{abstract}

Correspondence to: Dr Carlos Echiburú-Chau, Centro de Investigaciones del Hombre en el Desierto (CODECITE-CIHDE), Avda. General Velásquez 1775, Edificio CIHDE Piso 2, Arica, Chile E-mail: cechiburu@cihde.cl

Key words: Senecio graveolens, Senecio nutans, Chachacoma, cytotoxicity, breast cancer, hypoxia, anticarcinogen, MnSOD the cytotoxic effect of the phytochemical extract was dependent on the basal MnSOD protein expression. Thus, cytotoxicity was increased when MnSOD levels were low, but resistance was evident when protein levels were high. Additionally, the crude extract seems to trigger cell death by a variety of processes, including autophagy, apoptosis and necrosis, in MCF-7 cells. In summary, $S$. graveolens extract possess anticancer activity displaying a specific cytotoxic effect on cancer cells, thus serving as a potential source of phytochemical compounds for cancer treatment.

\section{Introduction}

Despite important advances in early detection and treatment, breast cancer continues to be a relevant public health concern, currently being the second cause of cancer-related deaths in woman $(1,2)$. The lifetime risk for developing breast cancer is 1 in 8 for western countries, and resistance to radiation and drugs constitutes a major cause of mortality (3).

Although chemotherapy has become a routine in most anticancer regimens, this therapeutic approach is currently limited by the ability of cancer cells to develop resistance to conventional drugs, a phenomenon that is particularly common during the course of treatment of solid tumors. Therefore, the search for new compounds with selective anticancer activity continues to be an important driving force for the development and implementation of novel anticancer therapies. Ideally, any anticancer drug should have an acceptable therapeutic index, that is, the drug should exert a cytotoxic effect on malignant cells with a minimal effect on normal cells. In this context, plants that for centuries have been used as part of folk medicine are unique sources of natural and bioactive compounds with potential anticancer effect (4). Indeed, numerous anticancer drugs in current use have been extracted from plants, including vinblastine, an alkaloid extracted from Catharanthus roseus that inhibits the assembly of the mitotic 
spindle microtubules (5), and paclitaxel, an alkaloid extracted from Taxus brevifolia whose activity stabilizes microtubules during cell division (6). Several other drugs extracted from plants have recently proven useful as anticancer therapies, including betolunic acid (7), resveratrol (8) and homoharringtotine (9), among others.

Senecio graveolens, also known as Chachacoma, is a herb that inhabits the Andes Mountains in South America, thriving in regions located 3,500 meters above the sea level. It belongs to the group Senecioneae, Asteraceae comprised of more than 900 species in Chile; Senecio comprises almost all 200 species, the richest gender in Chile. The ethnobotanic resources are used regularly for their medicinal properties in wound healing, as antiemetics, as anti-inflammatory agents, and as a means to ameliorate altitude sickness (principally as a vasodilator preparations) (10-12).

Pyrrolizidine alkaloids (PA), eremophilanolides and cacalolides are characteristic compounds isolated from Senecio species (13). Although the toxic effects exhibited by these plants have been largely attributed to their content of PA (14) the development of oxidative stress and the consequent generation of reactive oxygen species (ROS) and ROS-mediated cellular damage $(15,16)$, likely also contribute to toxicity.

Hypoxia is a pathophysiologic feature of nearly half of all locally advanced tumors (17). In particular, it is believed that up to one third of breast tumors are chronically subjected to hypoxic conditions (18). While the hypoxic microenvironment may serve as a selection barrier that allows the emergence of tumor cells with enhanced resistance to anticancer drugs $(19,20)$, hypoxia may also sensitize cancer cells to the cytotoxic effects of ROS generated by some chemotherapeutic drugs (20). Thus, the tumor microenvironment can determine the outcome of the pre-clinical assessments of potential chemotherapeutic agents.

The main goals of this study were to characterize the cytotoxic effect induced by an important ethnopharmacology resource called Chachacoma ( $S$. graveolens), and to explore the possible mechanisms responsible for the induction of cell death. The ethanolic extract and its major compound were evaluated in breast cancer cell lines under normoxic and hypoxic conditions.

\section{Materials and methods}

Plant material and crude extract. The $S$. graveolens was collected from a region near the Chungará lake in the North of Chile $\left(18^{\circ} 12^{\prime} 55^{\prime \prime} \mathrm{S} ; 69^{\circ} 17^{\prime} 40^{\prime \prime} \mathrm{O}\right)$ at 4,500 meters above the sea level. Approximately $180.87 \mathrm{~g}$ of dry and ground plant material (principally flowers, leaves and stems) were macerated in $95 \%$ ethanol for $72 \mathrm{~h}$. The extract was then filtered, concentrated under reduced pressure at $40^{\circ} \mathrm{C}$, and subjected to separation with a mixture of ethyl acetate/water $(500 \mathrm{ml}$ each). The resulting organic phase was finally concentrated under reduced pressure, resulting in a yield of $54.86 \mathrm{~g}$ of crude extract.

Purification and identification of major compounds. The organic phase $(20 \mathrm{~g})$ was separated by column chromatography using silica gel G-60 as stationary phase. As a mobile phase, a gradient of increasing polarity based on mixing hexane: ethyl-acetate applying gradients with increasing polarity from 49:1 to 1:49 were used. Following analysis with thin layer chromatography (TLC), samples with similar constitution were pooled and concentrated under reducing pressure. The resulting crystalline product was recrystallized using $\mathrm{EtO}_{2}: \mathrm{MeOH}(1: 1)$. A total of $2.42 \mathrm{~g}$ of pure compound ( $12.1 \%$ yield from the crude extract) was obtained from the original concentrated organic phase isolated form the crude plant material, $\mathrm{mp} 94-95^{\circ} \mathrm{C}$. In order to identify major compounds, the 1H, 13C (DEPT 135), sel. 2D HSQC and $2 \mathrm{D} \mathrm{HMBC}$ spectra were recorded in $\mathrm{CDCl} 3$ solutions on a Bruker Avance 400 Digital nuclear magnetic resonance (NMR) spectrometer.

Cell culture and cytotoxic assays. Four human breast cancer cell lines were used in this study: MCF-7, ZR-75-1 and MDA-MB-231, and the non-tumorigenic MCF-10F cell lines. All cell lines were obtained from the American Type Culture Collection (ATCC). Cells were cultured in specific media according to ATCC recommendations. When required, cells were incubated under hypoxic conditions $\left(1 \% \mathrm{O}_{2}\right)$, thus mimicking the in vivo tumor microenvironment. In both cases the incubation condition was established at $37^{\circ} \mathrm{C}$, humid atmosphere and $5 \% \mathrm{CO}_{2}$.

The cytotoxic effect of the $S$. graveolens extract was assessed in MCF-10F cells in a dose- and time-dependent manner. Cells $\left(1 \times 10^{4}\right.$ and $\left.4 \times 10^{4}\right)$ cultured under normoxic and hypoxic conditions, respectively, were seeded in 24-well plates in quadruplicate and then incubated for 4 days until $70 \%$ confluence. After this incubation period, cells were exposed to concentrations of the $S$. graveolens extract ranging from 0 to $1,600 \mu \mathrm{g} / \mathrm{ml}$ (dissolved in $0.5 \%$ DMSO). The effect of each concentration was assayed for 4, 12, 24 and $48 \mathrm{~h}$. In addition, MCF-10F cells were exposed to the major compound dissolved in ethanol $(50 \%)$ at concentrations ranging from 0 to $96.8 \mu \mathrm{g} /$ $\mathrm{ml}$. Cell viability was assessed using neutral red uptake assay after $24 \mathrm{~h}$ of treatment.

Western blot analyses. Cell lysates were prepared by using extraction buffer [50 mM Tris- $\mathrm{HCl}, \mathrm{pH} 8.0,130 \mathrm{mM} \mathrm{NaCl}$, $1 \%(\mathrm{w} / \mathrm{v}) \mathrm{NP} 40,1 \mathrm{mM}$ phenylmethylsulfonyl fluoride, $5 \mathrm{mM}$ $\mathrm{MgCl}_{2}$, and $1 \mathrm{mM}$ orthovanadate]. Proteins (40 $\mu \mathrm{g}$ ) were separated by SDS-PAGE and electroblotted onto PVDF membrane. The membrane was blocked in 5\% non-fat dry milk in TBST for $1 \mathrm{~h}$ at room temperature and incubated overnight with the following primary antibodies: MnSOD (sc-133134), caspase-8 (sc-7890), caspase-3 (sc-7272), and MAP LC3 $\alpha / \beta$ (sc-292354) (Santa Cruz Biotechnology, Santa Cruz, CA, USA) (dilution 1:500-1:1,000). HP-conjugated secondary antibodies (anti-mouse and anti-rabbit) (Santa Cruz Biotechnology) were used at a dilution of 1:5,000. Signals were detected using the ECL kit Super Signal West Pico Chemiluminescent Substrate (Thermo Scientific, Rockford, IL, USA) according to the company's protocol and recorded in Kodak BioMax light film (Sigma-Aldrich, St. Louis, MO, USA). $\beta$-actin (A5318) (SigmaAldrich) was used as loading control (dilution 1:20,000).

Transmission electron microscopy (TEM). A cell pellet was collected following scrapping of adherent cells. The pellet was 
A

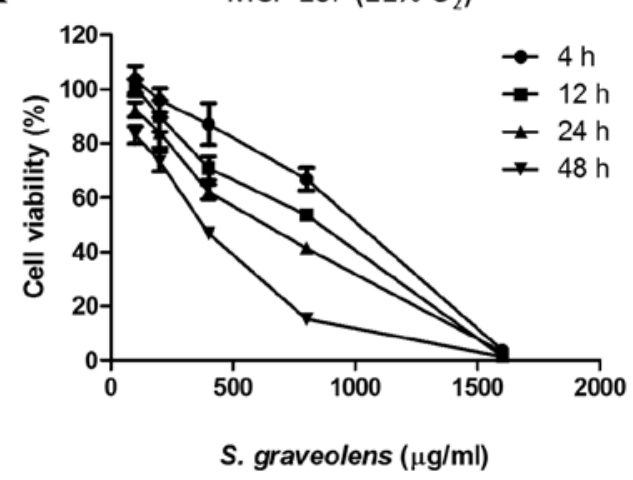

B MCF-10F $\left(1 \% \mathrm{O}_{2}\right)$

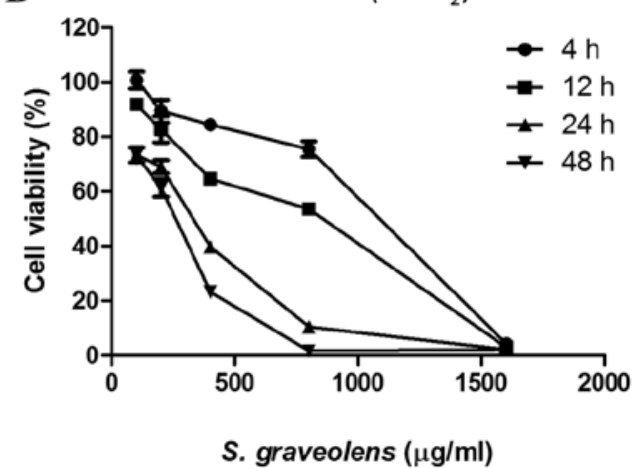

D

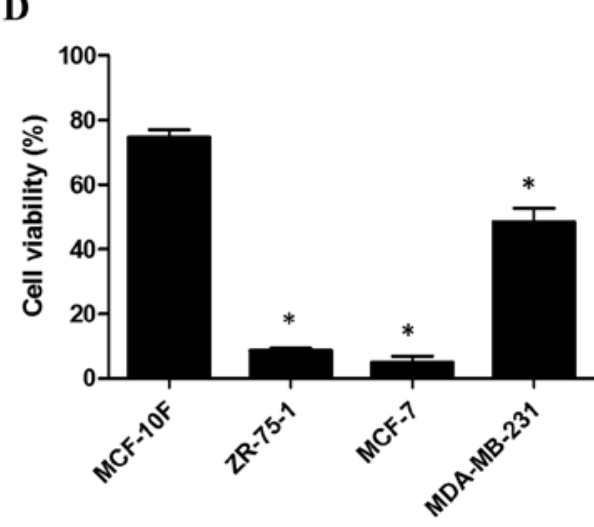

Figure 1. Effect of the $S$. graveolens EtOH extract on cell viability. MCF-10F was treated with different doses of $S$. graveolens extract (0-1.6 mg/ml) at different times $(0,4,12,24$ and $48 \mathrm{~h})$, incubated at $(\mathrm{A})$ normoxic $\left(21 \% \mathrm{O}_{2}\right)$ and $(\mathrm{B})$ hypoxic $\left(1 \% \mathrm{O}_{2}\right)$ condition. Cell viability was measured by neutral red uptake assay showing to be more pronounced under hypoxia. (C) $\mathrm{LD}_{50}$ calculated from dose-response curves under normoxic and hypoxic conditions were compared. The differential effect was enhanced under hypoxia in comparison to normoxia at 24 and $48 \mathrm{~h}$. (D) MCF-10F, ZR-75-1, MCF-7 and MDA-MB-231 cell lines were treated with $200 \mu \mathrm{g} / \mathrm{ml}\left(\mathrm{LD}_{25}\right)$ of crude extract during $24 \mathrm{~h}$ under hypoxia. The crude extracts induced specific cytotoxicity on breast cancer cell lines. $\mathrm{P}<0.05$, significantly different by one-way ANOVA followed by Dunnett's test.

washed two times with PBS and then fixed in $2 \%$ gluteraldehyde/50 mM sodium phosphate, $\mathrm{pH} 7.0$, at room temperature. Sample processing and image capture was carried out at The Advanced Microscopy Unit of the Pontificia Universidad Católica de Chile.

Statistical analysis. Numerical data were expressed as the average \pm standard error of the mean (SEM). Comparison between treated groups and controls was carried out by ANOVA and Dunnet's test. A $\mathrm{P}<0.05$ was considered to be significant. The lethal dose at $50 \%\left(\mathrm{LD}_{50}\right)$ was calculated by a non-linear regression curve with the use of GraphPad Prism 5.0 for Windows (GraphPad Software, San Diego, CA, USA).

\section{Results}

Differential cytotoxicity effect is caused by synergism between $S$. graveolens extract and hypoxia. The viability of MCF-10F cells treated with the ethanolic extract of $S$. graveolens was assessed by neutral red uptake under normoxic and hypoxic conditions in a concentration- and time-dependent manner (Fig. 1A and B). As shown in Fig. 1A and B, the cytotoxic effect was more pronounced in cells subjected to hypoxia compared to cells maintained under normoxic conditions.
Thus, compared to cells exposed to $21 \%$ oxygen, treatment with the phytochemical extract led to a significant reduction in $\mathrm{LD}_{50}$ values $(\mathrm{P}<0.05)$ in cells that were undergoing hypoxia (1\% oxygen). This reduction in cell viability was more pronounced at $24 \mathrm{~h}$ of treatment, reaching $48 \%$ of the values obtained under normoxia (Fig. 1C).

We next tested the effect of $200 \mu \mathrm{g} / \mathrm{ml}$ of A S. graveolens, a dose that corresponds to the $\mathrm{LD}_{25}$ for MCF-10F cells, on three tumorigenic mammary epithelial cells lines. Cells were maintained under hypoxic conditions and their viability measured $24 \mathrm{~h}$ after initiating treatment. Such conditions were considered the most effective and less harmful for MCF-10F, which was set as our control. This treatment led to a significant reduction in cell viability $(\mathrm{P}<0.05)$ of all the malignant cell lines in comparison to its non-tumorigenic counterpart. As shown in Fig. 1D, the viability of ZR-75-1 and MCF-7 cells was reduced to 9 and $6 \%$, respectively. However, the viability of MDA-MB-231 cells diminished only by $50 \%$.

Cytotoxicity elicited by 1-[4-hydroxy-3-(3-methylbut-2-enyl) phenyl]ethanone. Using H-NMR, we have previously identified 1-[4-hydroxy-3-(3-methylbut-2-enyl)phenyl]ethanone $\left(\mathrm{C} 13 \mathrm{H1}_{6} \mathrm{O}_{2}\right.$; MW: 204,26884 $\left.\mathrm{g} / \mathrm{mol}\right)$, also known as prenilated acetophenone, as the major compound present at the organic phase of extracts from $S$. graveolens. The working dose of 

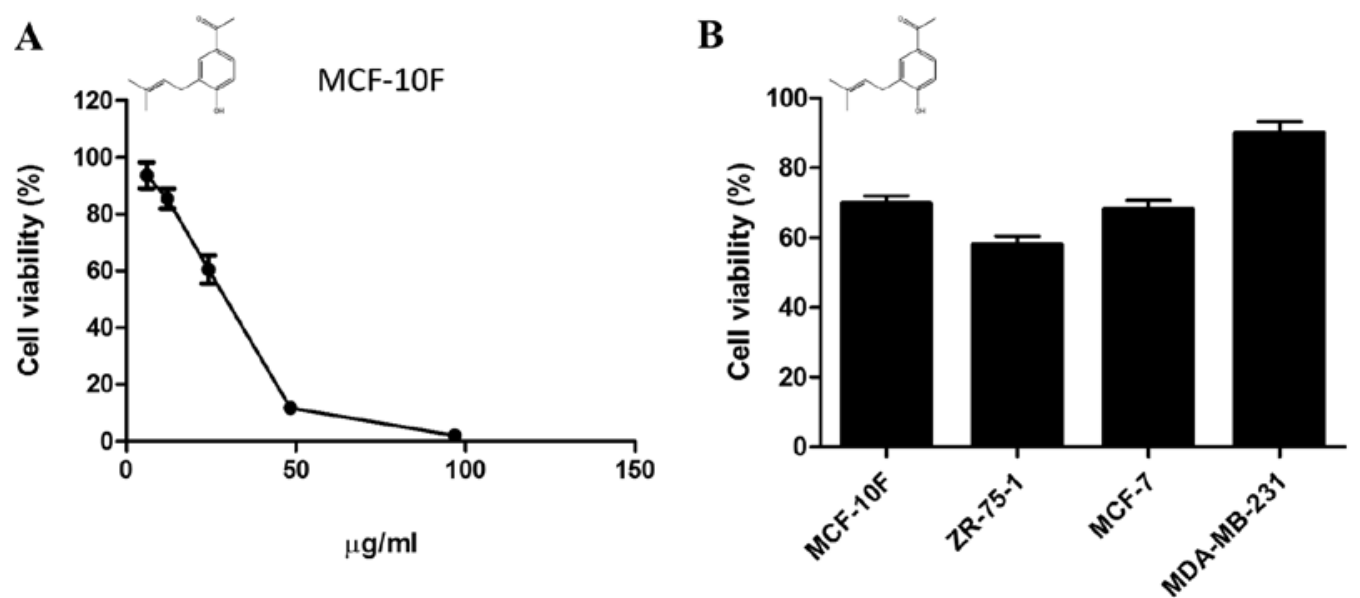

Figure 2. Effect of the 1-[4-hydroxy-3-(3-methylbut-2-enyl)phenyl]ethanone on cell viability. (A) MCF-10F was treated with different doses of 1-[4-hydroxy-3(3-methylbut-2-enyl)phenyl]ethanone $(0-96.8 \mu \mathrm{g} / \mathrm{ml})$ and viability measured at $24 \mathrm{~h}$ after treatments under hypoxic condition (1\% $\left.\mathrm{O}_{2}\right)$. (B) MCF-10F, ZR-75-1, MCF-7 and MDA-MB-231 cell lines were treated with $13.8 \mu \mathrm{g} / \mathrm{ml}\left(\mathrm{LD}_{25}\right)$ of the 1-[4-hydroxy-3-(3-methylbut-2-enyl)phenyl]ethanone and viability measured at $24 \mathrm{~h}$ after treatment under hypoxic. The $S$. graveolens extract induced cytotoxicity only in ZR-75-1 cells, but in general the effect was inefficient in comparison with the whole extract exposure.

prenilated acetophenone, corresponding to $\mathrm{LD}_{25}$ for MCF-10F $(13.8 \mu \mathrm{g} / \mathrm{ml})$, was estimated by a dose-response curve (Fig. 2A). The compound was then added to the media of breast cancer cells growing under hypoxic conditions and the viability was measured $24 \mathrm{~h}$ later. Overall, the prenilated acetophenone was more cytotoxic than the crude extract. However, the compound was unable to reduce cell viability of malignant cells under hypoxic conditions ( $1 \%$ oxygen) in a proportion similar to that shown by the extract (Fig. 2B).

Low MnSOD expression is associated with sensitivity to the cytotoxic effect of the extract. The cytotoxicity elicited by certain phytochemicals from Senecio species, in synergism with hypoxia, could be dependent on the ability of the cell to respond to the cellular damage induced by oxidative stress. Therefore, we set out to examine the relationship between the cytotoxic induced by $S$. graveolens and MnSOD expression, an important mitochondrial antioxidant enzyme recognized as relevant in detoxification system from free radicals. As shown in Fig. 3A, the protein levels of MnSOD did not change in response to the phytochemical treatment. However, the basal expression of MnSOD correlated well with the degree of cytotoxicity observed in the different cell lines, with the highest levels of cytotoxicity observed in cells with reduced expression of MnSOD (Figs. 1D and 3A).

Caspases and MAP LC3 expression after S. graveolens treatment. We next studied the cellular processes that might be responsible for the cytotoxic effects of $S$. graveolens. Apoptosis is the result of the recruitment and activation of cysteine-aspartic acid proteases (caspases) and caspase- 8 is the most upstream protease involved in the extrinsic apoptotic pathway. Activated caspase- 8 (subunit p18, $18 \mathrm{kDa}$ ) and its inactive precursor pro-caspase- $8(55 \mathrm{kDa})$ were overexpressed in MCF-7 cells following exposure to $S$. graveolens extract (Fig. 3B). In contrast, caspase-8 levels were reduced in MDA-MB-231 cells in response to the extract. The expression of caspase-3 is known to be abrogated in MCF-7 cells, as
$\mathbf{A}$
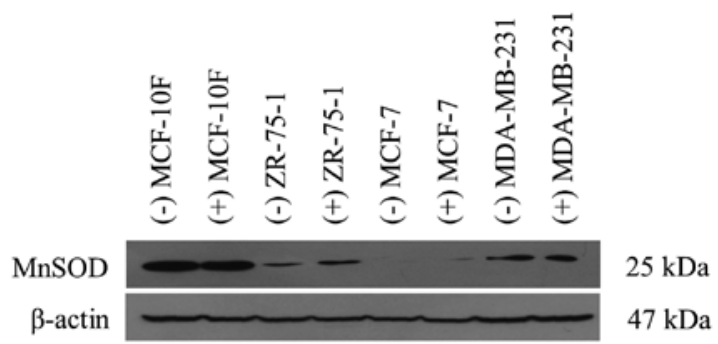

B

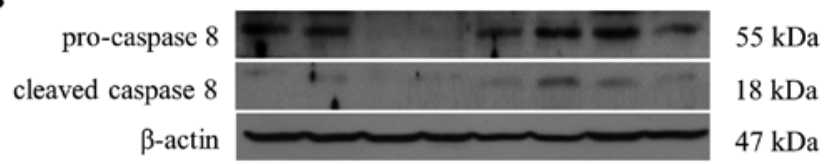

C

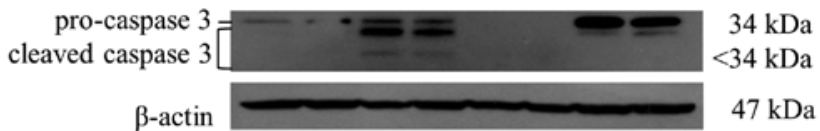

D

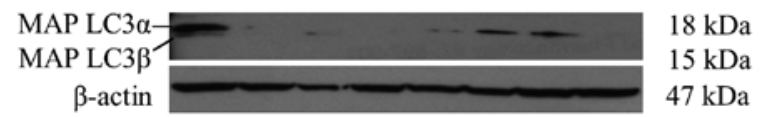

Figure 3. Effect of $S$. graveolens treatment on pivotal proteins. MCF-10F, ZR-75-1, MCF-7 and MDA-MB-231 cell lines were treated with S. graveolens extract $\left(200 \mu \mathrm{g} / \mathrm{ml}, 24 \mathrm{~h}, 1 \% \mathrm{O}_{2}\right)$ and protein expression was evaluated by western blotting for MnSOD, caspase-8, caspase-3 and MAPLC3 proteins. $\beta$-actin was used as a loading control. Mostly differences after treatment were observed in MCF-7 and MDA-MB-231 cell lines. (-), nontreated; $(+)$, treated.

confirmed in Fig. 3C. On the other hand, cleaved caspase-3 $(<34 \mathrm{kDa})$ was observed in ZR-75-1 cells, indicating initiation of the apoptotic process. In contrast, MDA-MB-231 cells displayed overexpression of pro-caspase-3 $(34 \mathrm{kDa})$, but not the cleaved isoform.

We next checked the levels of MAP LC $3 \alpha$ and $\beta$ proteins, which are indicative of autophagosome formation and widely 
A

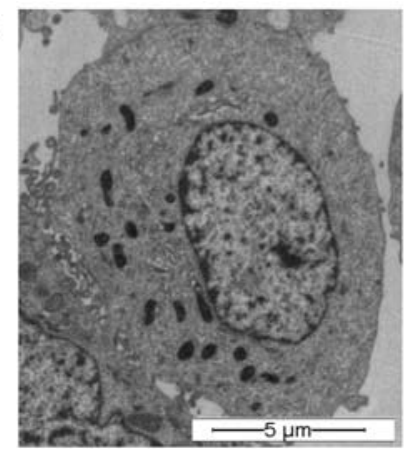

D

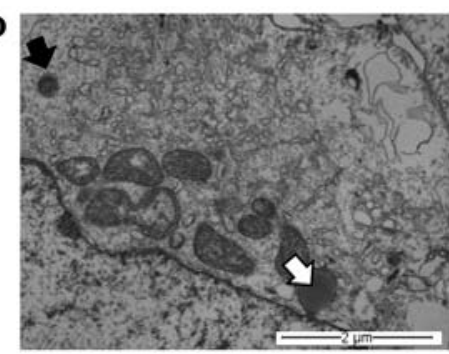

B

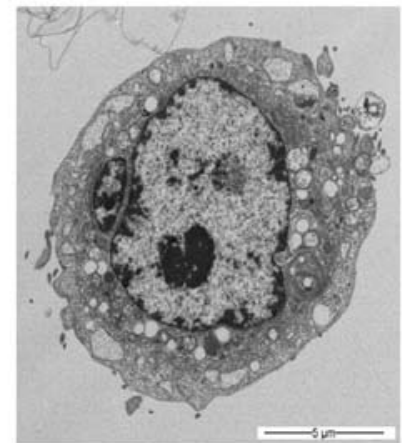

E

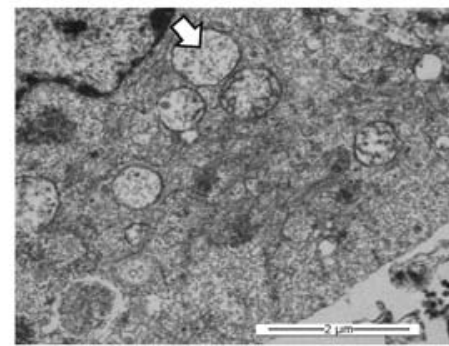

C

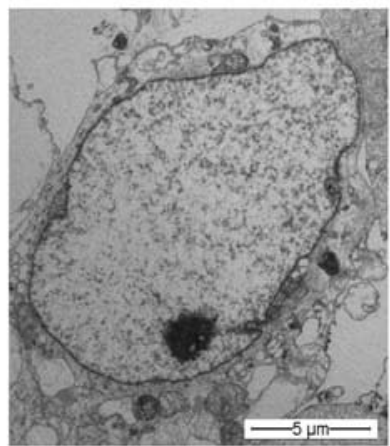

$\mathbf{F}$

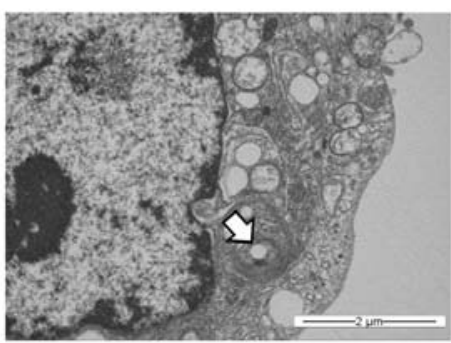

Figure 4. Effect of S. graveolens on structural changes of MCF-7 under normoxia. MCF-7 was treated with $100 \mu \mathrm{g} / \mathrm{ml}$ of the $S$. graveolens extract and observed by electronic microscopy. Representative image shows features that correspond to (B) necrosis components and (C) cellular digestion. The structural changes were characterized by lysosomes in different stages of maturation, mainly (D) primary lysosomes (white arrow) and residual bodies (black arrow), (E) vacuoles (white arrow) and (F) lamellar bodies (white arrow).

used as markers of autophagy. Autophagy is a cellular catabolic degradation response to starvation or stress whereby cellular components are engulfed, digested and recycled to sustain cellular metabolism (11). Most evidence supports a role for autophagy in sustaining cell survival, but it is possible to observe cell death as a result from progressive cellular consumption attributed to a continued autophagy (21). As shown in Fig. 3C, both MAP LC $3 \alpha$ and MAP LC3 $\beta$ were downregulated in MCF-10F and MDA-MB-231 cell lines. However, MAP LC3 $\beta$ was overexpressed in MCF-7 cells after extract exposure. Under these conditions, we could not detect MAP LC3 in ZR-75-1 cells. Taken together, the cytotoxic effects induced by $S$. graveolens in MCF-7 cells can be mechanistically linked to autophagic and apoptotic initiation. Further work will be necessary to define the relative contribution of these processes to the final cytotoxic effect elicited by S. graveolens.

Synergism between $S$. graveolens and hypoxia leads to cell death in MCF-7 cells. Our findings (Fig. 3C) suggest that the extract might trigger the autophagic process in MCF-7 cells subjected to hypoxia. To confirm the presence of a digestive process, and specifically the presence of autophagy, an ultrastructural analysis using transmission electron microscopy was carried out. At first, these experiments were performed under normoxic conditions $\left(21 \% \mathrm{O}_{2}\right)$ to rule out any cellular change induced by oxygen concentration. MCF-7 cells were treated with $100 \mu \mathrm{g} / \mathrm{ml}$ of the $S$. graveolens extract (half $\mathrm{LD}_{25}$ dose). TEM analysis of treated cells revealed ultrastructural signs suggestive of cellular digestion (Fig. 4B) and necrosis (Fig. 4C), when compared with controls (Fig. 4A). These changes were characterized by the presence of lysosomes in different stages of maturation, including primary lysosomes and residual bodies (Fig. 4D), vacuoles (Fig. 4E) and lamellar bodies (white arrow) (Fig. 4F).

The synergistic effects of hypoxia $\left(\begin{array}{lll}1 \% & \mathrm{O}_{2}\end{array}\right)$ and the S. graveolens extract were then studied at the ultra-structural level. Representative images revealed apoptotic components (Fig. 5A) coexisting with necrosis (Fig. 5B) in almost all the samples analyzed, regardless of the presence of extract. Nonetheless, cells treated with $S$. graveolens triggered necrosis to a greater extent compared with non-treated cells, the latter showing features of apoptotic cell death. Overall, necrotic cells were characterized by the presence of swollen mitochondria and disruption of mitochondrial crests (Fig. 5C), including swollen vacuole morphology (Fig. 5D). In spite of this complex morphologic scenario, it was still possible to observe signs of intracellular digestion in treated cells, including lysosomes in different stages of maduration. Thus, primary lysosomes (Fig. 5E), autolysosomes (Fig. 5F) and residual bodies (Fig. 5G) were frequent findings in these cells. Moreover, autophagosomes were also observed in treated cells in major frequency in comparison to non-treated cells (Fig. 5H).

\section{Discussion}

To our knowledge, this is the first report describing the cytotoxic effects induced by the ethanolic extract of $S$. graveolens on breast cancer cell lines. This phytochemical extract induced a cytotoxic effect against breast cancer cells, but failed to have similar effects on non-tumorigenic cells.

The cytotoxic effect induced by $S$. graveolens extract in malignant cells was prominent when these cells were maintained under hypoxia in comparison with the same cells maintained under normoxic conditions. 
A

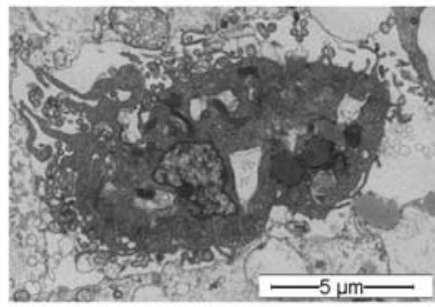

D

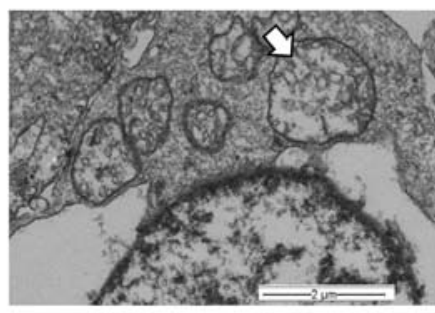

B

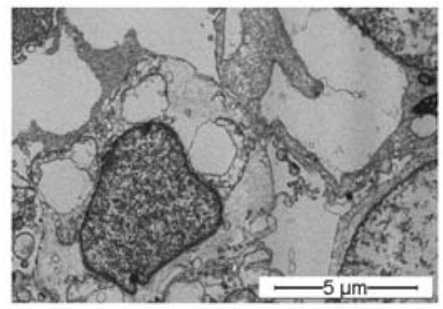

E

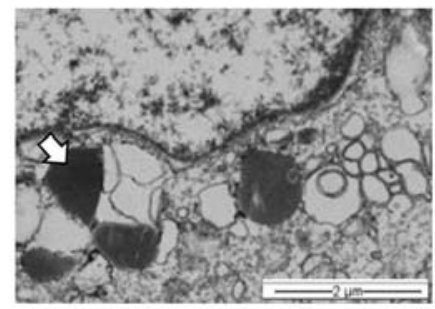

C

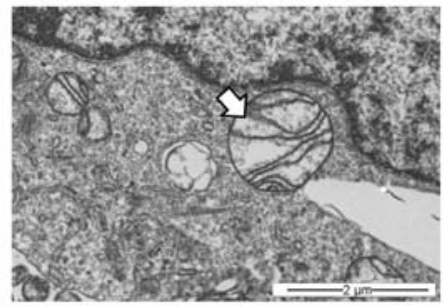

$\mathbf{F}$

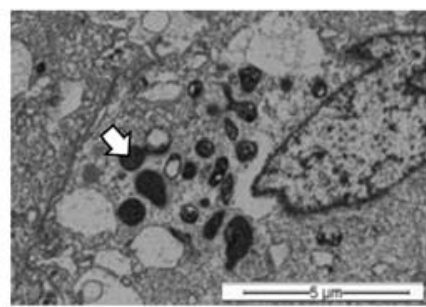

G

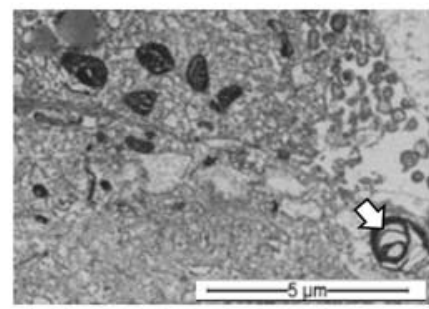

$\mathbf{H}$

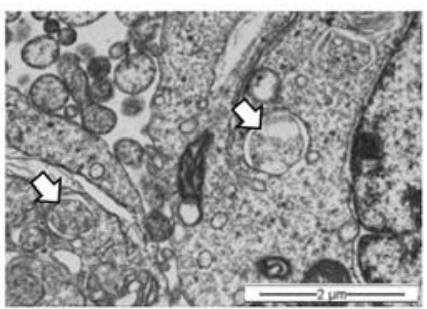

Figure 5. Effect of $S$. graveolens on structural changes of MCF-7 under hypoxia. MCF-7 was treated with $100 \mu \mathrm{g} / \mathrm{ml}$ of the $S$. graveolens extract and observed by electronic microscopy. Representative image shows features that correspond to (A) apoptotic component coexisting with (B) necrosis. Necrosis features characterized by (C) swollen mitochondria (white arrow) and (D) swollen vacuole (white arrow) in almost all the samples with or without treatments. Representative image shows intracellular digestion findings in treated cells characterized by (E) primary lysosomes (white arrow), (F) autolysosomes (white arrow) and (G) residual bodies (white arrow). (H) Autophagosomes (white arrow) were observed in treated cells in major frequency in comparison to non-treated cells.

Our study takes advantage of intrinsic differences in response between non-tumorigenic and malignant cells exposed to hypoxia. In these settings, hypoxia seems to enhance the sensitivity of malignant cells to $S$. graveolens treatment. By itself, hypoxia is able to stimulate release of ROS bursts through mitochondria $(10,22)$, which in turn could explain the greater sensitivity of cells to certain drugs with the resulting enhancement of the cytotoxic effects. On the other hand, a dose of $200 \mu \mathrm{g} / \mathrm{ml}$ was able to reduce the cell viability by more than $90 \%$ in MCF-7 and ZR-75-1 cell lines. Other methanolic extracts, e.g. from Senecio stabianus, have the ability of inhibit the cell viability on MCF-7 cell line $\left(\mathrm{IC}_{50} 91.1 \mu \mathrm{g} / \mathrm{ml}\right)$ under normoxic environment, but was not compared with a normal counterpart (23).

Previous reports have shown that the highly aggressive MDA-MB-231 cells, which do not express estrogen receptor, progesterone receptor, and do not have HER-2/Neu amplification (triple-negative), growing under hypoxic conditions, are able to control the tumor $\mathrm{pH}$, as well as the hypoxia-induced extracellular acidosis, thus allowing aggressive tumor cells to survive the hostile environment imposed by hypoxia $(24,25)$. Since restriction of oxygen may increase superoxide metabolism (26) and phytochemicals extracts belong from Senecio species produce reactive oxygen species (ROS) (15), we also investigated whether hypoxia and $S$. graveolens extract may influence superoxide dismutase expression, enzyme that removes superoxide radicals $\left(\mathrm{O}_{2}{ }^{\circ}\right)$ and produces hydrogen peroxide $\left(\mathrm{H}_{2} \mathrm{O}_{2}\right)$, as the first step to detoxify the environment from radical oxygen species (27). The expression of MnSOD was not altered by hypoxia or S. graveolens. However, the cellular response to these treatments was dependent on the basal levels of this enzyme. Thus, cells with higher levels of basal MnSOD were able to better survive $S$. graveolens exposure, compared to those showing lower levels of MnSOD. These findings are in line with the fact that a high MnSOD content in tumor cells is associated with a more aggressive and metastatic phenotype (28). Moreover, cytotoxicity studies have revealed that MCF-10F and MDA-MB-231 cells are resistant to the drug metformin, and this resistance is accompanied by increased levels of MnSOD. In contrast, MCF-7 cells, which are sensitive to metformin, display low MnSOD expression (29). Moreover, tumor cells with high MnSOD content are associated with invasive and metastatic profiles (30,31). Based on these findings, the authors (32) proposed that inhibition of superoxide dismutase may provide a potential alternative to eliminate cancer cells.

Another novel finding was the synergistic effect of hypoxia and $S$. graveolens extract in triggering apoptosis, necrosis, as well as the self-digestion process known as autophagy. This catabolic process is characterized by the sequestration of bulk cytoplasm, proteins and organelles in double-membrane vesicles, known as autophagosomes, which are carried to lysosomes for degradation (33). Autophagy plays a pivotal role in countless processes, including cellular starvation, cellular differentiation, cell death, aging, innate immunity and as a mechanism of cell death during embryonic development (34). Although primarily considered a mechanism of survival (35), 
several reports have suggested that autophagic cell death may precede apoptosis in some cancer cells treated with antitumor agents (36). The distinction between apoptosis and autophagy as mechanisms of programmed cell death is not always clear, with several cases of autophagy (also known referred to as type II cell death) showing also traits of apoptosis (37). Presently, it is not clear whether the autophagic events observed in MCF-7 cells have a protective role or, alternatively, they represent the initial steps of an apoptotic process. Furthermore, the apoptotic process observed by electron microscopy in MCF-7 cells may be the consequence of increased expression of caspase- 8 , a fact reported in cases in which ROS-dependent activation of caspase- 8 contributed to apoptosis initiation (22). However, based on the expression levels of cleaved caspase- 3 observed in ZR-75-1 cells, the $S$. graveolens extract might trigger apoptosis but is not clear if autophagic events exist.

The coexistence of necrosis together with variable levels of apoptosis and autophagy has been reported in other studies in which the effect of an anticancer drug seemed to depend on ROS production (11). It is then possible that hypoxia by itself triggers necrosis through ROS formation, an effect that is further enhanced by the use of Senecio species (38).

The resistance to cell death observed in MDA-MB-231 cells seems to be related to the diminished expression in cleaved caspase- 8 after phytochemical treatment, an observation that was corroborated by the absence of cleaved caspase- 3 . Likewise, the reduced expression of markers of autophagy in MDA-MB-231 cells following $S$. graveolens treatment indicates a loss in the ability of these cells to upregulate autophagy. Thus, the mechanisms responsible for the cytotoxicity exerted by the plant extract are presently unclear. It is very likely that the relative contribution of apoptosis and autophagy to the cytotoxic effects of $S$. graveolens is chiefly dependent on the genetic profile of the cells tested, as alterations in known oncogenic pathways (e.g., p53) modify the way in which a cell responds to external stimuli.

It has been reported that some members of the Senecio genus produce pyrrolizidine alkaloids as the main metabolites (39). Since these substances can cause important hepatotoxic effects under certain conditions $(38,40,41)$, there is a growing necessity to identify and isolate active cytotoxic compounds from Senecio that can have anticancer effects without affecting normal tissues.

Our results suggest that the cytotoxic activity of the ethanolic extract obtained from $S$. graveolens is specific towards human breast cancer cells and can be enhanced by hypoxia, an effect that might be explained in part by its ability to induce a variety of processes, including autophagy, apoptosis and necrosis in tumor cells. Overall, this study supports the potential use of $S$. graveolens as a source of anticancer drugs. Efforts to isolate the biologically active compound from these extracts are currently under way in our laboratory.

\section{Acknowledgements}

We are grateful to Dr Mario Valenzuela from Universidad de Tarapacá for the laboratory facilities. We also appreciate the Emilio Gutierrez advice in ethnopharmacological plants. This study was supported by grant from FONDECYT (no 11110284) (CECH). We also thank CODECITE-CIHDE.

\section{References}

1. Greenlee RT, Hill-Harmon MB, Murray T and Thun M: Cancer statistics, 2001. CA Cancer J Clin 51: 15-36, 2001.

2. Choi S, Lim MH, Kim KM, Jeon BH, Song WO and Kim TW: Cordycepin-induced apoptosis and autophagy in breast cancer cells are independent of the estrogen receptor. Toxicol Appl Pharmacol 257: 165-173, 2011.

3. Ward C, Langdon SP, Mullen P, et al: New strategies for targeting the hypoxic tumour microenvironment in breast cancer. Cancer Treat Rev 39: 171-179, 2013.

4. Mishra BB and Tiwari VK: Natural products: an evolving role in future drug discovery. Eur J Med Chem 46: 4769-4807, 2011.

5. Makarov AA, Tsvetkov PO, Villard C, et al: Vinflunine, a novel microtubule inhibitor, suppresses calmodulin interaction with the microtubule-associated protein STOP. Biochemistry 46: 14899-14906, 2007.

6. Cisternino S, Bourasset F, Archimbaud Y, Semiond D, Sanderink G and Scherrmann JM: Nonlinear accumulation in the brain of the new taxoid TXD258 following saturation of P-glycoprotein at the blood-brain barrier in mice and rats. Br J Pharmacol 138: 1367-1375, 2003.

7. Fulda S: Betulinic acid for cancer treatment and prevention. Int J Mol Sci 9: 1096-1107, 2008.

8. Garcia-Zepeda SP, Garcia-Villa E, Diaz-Chavez J, HernandezPando R and Gariglio P: Resveratrol induces cell death in cervical cancer cells through apoptosis and autophagy. Eur J Cancer Prev 22: 577-584, 2013.

9. Zhou DC, Zittoun R and Marie JP: Homoharringtonine: an effective new natural product in cancer chemotherapy. Bull Cancer 82: 987-995, 1995.

10. Guzy RD and Schumacker PT: Oxygen sensing by mitochondria at complex III: the paradox of increased reactive oxygen species during hypoxia. Exp Physiol 91: 807-819, 2006.

11. Kim Y, Jeong IG, You D, et al: Sodium meta-arsenite induces reactive oxygen species-dependent apoptosis, necrosis, and autophagy in both androgen-sensitive and androgen-insensitive prostate cancer cells. Anticancer Drugs 25: 53-62, 2014.

12. Villagrán $C$ and Castro V: Ciencia indigena de los andes del norte de Chile - Senecio nutans. Editorial Universitaria S.A, Santiago, Chile, 2004.

13. Burgueno-Tapia E, Hernandez LR, Resendiz-Villalobos AY and Joseph-Nathan P: Conformational evaluation and detailed $1 \mathrm{H}$ and 13C NMR assignments of eremophilanolides. Magn Reson Chem 42: 887-892, 2004.

14. Burgueno-Tapia E, Gonzalez-Coloma A, Martin-Benito D and Joseph-Nathan P: Antifeedant and phytotoxic activity of cacalolides and eremophilanolides. Z Naturforsch C 62: 362-366, 2007.

15. Bondan C, Soares JC, Cecim M, Lopes ST, Graca DL and da Rocha RX: Oxidative stress in the erythrocytes of cattle intoxicated with Senecio sp. Vet Clin Pathol 34: 353-357, 2005.

16. Kizaki M, Xian M, Sagawa M and Ikeda Y: Induction of apoptosis via the modulation of reactive oxygen species (ROS) production in the treatment of myeloid leukemia. Curr Pharm Biotechnol 7: 323-329, 2006.

17. Vaupel P, Mayer A and Hockel M: Tumor hypoxia and malignant progression. Methods Enzymol 381: 335-354, 2004.

18. Vaupel P, Briest $S$ and Hockel M: Hypoxia in breast cancer: pathogenesis, characterization and biological/therapeutic implications. Wien Med Wochenschr 152: 334-342, 2002.

19. Dong XL, Xu PF, Miao C, et al: Hypoxia decreased chemosensitivity of breast cancer cell line MCF-7 to paclitaxel through cyclin B1. Biomed Pharmacother 66: 70-75, 2012.

20. Li F, Huang L, Su XL, Gu QH and Hu CP: Inhibition of nuclear factor-kappaB activity enhanced chemosensitivity to cisplatin in human lung adeno-carcinoma A549 cells under chemical hypoxia conditions. Chin Med J 126: 3276-3282, 2013.

21. Reef S,Zalckvar E, Shifman O, et al: A short mitochondrial form of p19ARF induces autophagy and caspase-independent cell death. Mol Cell 22: 463-475, 2006.

22. Shi DY, Xie FZ, Zhai C, Stern JS, Liu Y and Liu SL: The role of cellular oxidative stress in regulating glycolysis energy metabolism in hepatoma cells. Mol Cancer 8: 32, 2009.

23. Tundis R, Loizzo MR, Bonesi M, et al: In vitro cytotoxic effects of Senecio stabianus Lacaita (Asteraceae) on human cancer cell lines. Nat Prod Res 23: 1707-1718, 2009.

24. Chen CL, Chu JS, Su WC, Huang SC and Lee WY: Hypoxia and metabolic phenotypes during breast carcinogenesis: expression of HIF-1alpha, GLUT1, and CAIX. Virchows Arch 457: 53-61, 2010. 
25. Lou Y, McDonald PC, Oloumi A, et al: Targeting tumor hypoxia: suppression of breast tumor growth and metastasis by novel carbonic anhydrase IX inhibitors. Cancer Res 71: 3364-3376, 2011.

26. Kaewpila S, Venkataraman S, Buettner GR and Oberley LW: Manganese superoxide dismutase modulates hypoxia-inducible factor-1 alpha induction via superoxide. Cancer Res 68: 2781-2788, 2008.

27. Allen RG and Balin AK: Effects of oxygen on the antioxidant responses of normal and transformed cells. Exp Cell Res 289 307-316, 2003

28. Ennen M, Minig V, Grandemange S, et al: Regulation of the high basal expression of the manganese superoxide dismutase gene in aggressive breast cancer cells. Free Rad Biol Med 50: 1771-1779, 2011.

29. Zhuang Y and Miskimins WK: Metformin induces both caspasedependent and poly(ADP-ribose) polymerase-dependent cell death in breast cancer cells. Mol Cancer Res 9: 603-615,2011.

30. Nelson KK, Ranganathan AC, Mansouri J, et al: Elevated sod2 activity augments matrix metalloproteinase expression: evidence for the involvement of endogenous hydrogen peroxide in regulating metastasis. Clin Cancer Res 9: 424-432, 2003.

31. Kattan Z, Minig V, Leroy P, Dauca M and Becuwe P: Role of manganese superoxide dismutase on growth and invasive properties of human estrogen-independent breast cancer cells. Breast Cancer Res Treat 108: 203-215, 2008.

32. Hileman EA, Achanta G and Huang P: Superoxide dismutase: an emerging target for cancer therapeutics. Expert Opin Ther Targets 5: 697-710, 2001.
33. Klionsky DJ: Autophagy revisited: a conversation with Christian de Duve. Autophagy 4: 740-743, 2008.

34. Bowen ID, Mullarkey K and Morgan SM: Programmed cell death during metamorphosis in the blow-fly Calliphora vomitoria. Microsc Res Tech 34: 202-217, 1996.

35. Mathew R, Karantza-Wadsworth V and White E: Role of autophagy in cancer. Nat Rev Cancer 7: 961-967, 2007.

36. Codogno P and Meijer AJ: Autophagy and signaling: their role in cell survival and cell death. Cell Death Differ 12 (Suppl 2): 1509-1518, 2005.

37. Motyl T, Gajkowska B, Zarzynska J, Gajewska M and Lamparska-Przybysz M: Apoptosis and autophagy in mammary gland remodeling and breast cancer chemotherapy. J Physiol Pharmacol 57 (Suppl 7): 17-32, 2006.

38. Steenkamp V, Stewart MJ, van der Merwe S, Zuckerman M and Crowther NJ: The effect of Senecio latifolius a plant used as a South African traditional medicine, on a human hepatoma cell line. J Ethnopharmacol 78: 51-58, 2001.

39. Loizzo MR, Tundis R, Statti GA, Menichini F and Houghton PJ: In-vitro antiproliferative effects on human tumour cell lines of extracts and jacaranone from Senecio leucanthemifolius Poiret. J Pharm Pharmacol 57: 897-901, 2005.

40. Hammond GB, Fernandez ID, Villegas LF and Vaisberg AJ: A survey of traditional medicinal plants from the Callejon de Huaylas, Department of Ancash, Peru. J Ethnopharmacol 61: 17-30, 1998.

41. Liu F and Ng TB: Antioxidative and free radical scavenging activities of selected medicinal herbs. Life Sci 66: 725-735, 2000. 